\title{
Effect of paracetamol (acetaminophen) on gastric ionic fluxes and potential difference in $\operatorname{man}^{1}$
}

\author{
K. J. IVEY AND P. SETTREE \\ From the Division of Gastroenterology, Harry S. Truman Memorial Veterans Hospital, University of \\ Missouri, Columbia, Missouri, and the Department of Gastroenterology, Royal Prince Alfred Hospital, \\ Sydney NSW, Australia
}

SUMMARY Paracetamol has replaced aspirin as the analgesic of choice in many situations. The major reason is the damaging effect of aspirin on gastric mucosa. Alterations in gastric ionic fluxes and potential difference provide measures of aspirin-induced structural damage. We studied the effect of large doses of paracetamol (acetaminophen $2.0 \mathrm{~g}$ ) on gastric ionic fluxes in man. In addition, the effect of $2.0 \mathrm{~g}$ paracetamol on gastric potential difference was compared with that of $600 \mathrm{mg}$ aspirin. In contrast with salicylates, paracetamol caused no significant alteration in movement of $\mathrm{H}^{+}$and $\mathrm{Na}^{+}$ions over control periods. Aspirin causes a significant fall in transmucosal potential difference (PD) across gastric mucosa of $15 \mathrm{mv}$, while paracetamol caused no significant change. Paracetamol in a dose four times that recommended does not alter gastric ionic fluxes or potential difference. These studies support choice of paracetamol as analgesic over aspirin where damage to gastric mucosa may be critical.

Use of aspirin as an analgesic is restricted by its damaging effect on gastric mucosa. Because of this, paracetamol (acetaminophen (USA); trade names: Panadol (Winthrop), Tylenol ${ }^{\mathrm{R}}$ (McNeil)) has replaced aspirin as analgesic of choice in many clinical situations. Most studies comparing the effect of aspirin and paracetamol on the human stomach have been indirect-for example, measurement of gastrointestinal bleeding (Goulston and Skyring, 1964). Vickers in 1967 found a 17\% incidence of visible gastroscopic lesions after aspirin compared with $0 \%$ after paracetamol. This study, however, seriously underestimated the incidence of aspirin-induced damage as measured by other techniques (Goulston and Skyring, 1964) including microscopic examination of gastric biopsies (Ivey et al., 1975a), which indicated damage in $100 \%$ of subjects.

Aspirin has been well documented to damage

${ }^{1}$ This work was supported in part by research grants from the US Veterans Administration and the National Health and Medical Research Council of Australia. The Clinical Research Center (UMMC) provided facilities for studying patients.

Address for reprint requests: Associate Professor K. J. Ivey, Division of Gastroenterology, Veterans Administration Hospital, University of Missouri Medical Center, Columbia, Missouri 65201, USA.

Received for publication 28 June 1976 gastric mucosa in animals and man by altering the gastric mucosal barrier to hydrogen ion movement (Davenport, 1965; Ivey et al., 1972a; Ivey and Gray, 1972b; Ivey et al., 1975b). Aspirin has also been shown to significantly reduce potential difference across gastric mucosa in man (Geall et al., 1970; Murray et al., 1974; Ivey et al., 1975a, b, c). No studies have been published in man directly measuring hydrogen ion movement and/or changes in potential difference after paracetamol.

We studied the direct effect of large 'analgesic' doses of paracetamol on human gastric mucosa as measured by changes in the gastric mucosal barrier to $\mathrm{H}^{+}$and $\mathrm{Na}^{+}$movement and transmucosal potential difference (PD). The effects on PD were compared with those of aspirin. In separate studies we have shown that changes in potential difference as an index of function of the gastric mucosal barrier correlate with gastric mucosal structural damage induced by aspirin in man (Ivey et al., 1975a).

\section{Methods}

SUBJECTS

Fifteen studies were carried out on five healthy volunteers aged 18-25 years; each was studied on three different occasions. The first study consisted of two parts, each carried out on a separate day. 916 
PD across gastric mucosa was measured after intragastric administration of (1) paracetamol, and (2) aspirin in saline. In the second study an acid test solution was instilled and net movement of $\mathrm{H}^{+}$and $\mathrm{Na}^{+}$ions measured and compared with effects on ionic flux of a solution with paracetamol. Potential difference was monitored throughout this study, also.

\section{TEST SOLUTION}

Study I Measurement of PD with saline solutions The control solution consisted of $100 \mathrm{ml}$ isotonic $\mathrm{NaCl}(154 \mathrm{mmol} / \mathrm{l})$. The test solution consisted of either (1) $2.0 \mathrm{~g}$ paracetamol or (2) $600 \mathrm{mg}$ (two $0.3 \mathrm{~g}$ tablets) aspirin suspended in $100 \mathrm{ml}$ isotonic $\mathrm{NaCl}$.

Study II Measurement of ionic fluxes The control solution consisted of $200 \mathrm{ml} 160 \mathrm{mEq} / 1 \mathrm{HCl}$, mean osmolality $307 \mathrm{mOsm} / \mathrm{kg}$, and radioactive chromium chloride $\left({ }^{51} \mathrm{Cr}, 25 \mu \mathrm{Ci} / \mathrm{l}\right)$ as non-absorbable indicator. The test solution contained in addition $2.0 \mathrm{~g}$ (four $0.5 \mathrm{~g}$ tablets) paracetamol ground into a suspension in $200 \mathrm{ml}$ of the acid control solution. A $200 \mathrm{ml}$ wash solution contained $160 \mathrm{mEq} / 1$ $\mathrm{HCl}$ only.

\section{EXPERIMENTAL TECHNIQUE, LABORATORY MEASUREMENTS, AND CALCULATIONS}

Study I Measurement of PD Gastric PD was measured by established methods (Andersson and Grossman, 1965; Ivey et al., 1975b). Reference electrode was a polyethylene tube filled with saturated $\mathrm{KCl}$ solution in 3\% agar, gas sterilised and placed in a peripheral vein through a 14 gauge needle. A similar electrode was attached to a nasogastric tube with the tips of the two tubes adjacent. It was placed under fluoroscopy in the gastric fundus near the greater curvature as previously described (Ivey and DenBesten, 1971). The position of the tip was monitored fluoroscopically at frequent intervals throughout the study. PD was recorded continuously throughout all studies with a Radiometer voltmeter connected to a Riken-Denshi strip-chart recorder. After removal of residual fasting gastric contents $100 \mathrm{ml}$ isotonic saline was instilled intragastrically and baseline PD recorded for $\mathbf{3 0}$ minutes. The test solution containing either paracetamol or aspirin was then instilled. Thirty minutes later the remaining gastric contents were aspirated. The residual volumes were small for both paracetamol and aspirin, most of the instilled solution having emptied through the pylorus. In separate studies where the gastric contents were not aspirated PD recordings were identical with those when aspiration was performed. Next the control saline solution was in- stilled and the PD recorded after another 30 minutes. Test period and saline periods were then each repeated in that order while PD was recorded continuously. Each study, therefore, consisted of either two paracetamol or two aspirin test periods and three control periods. Each of the five subjects was studied with the paracetamol and aspirin solutions on separate days several weeks apart and randomly allocated. Two subjects had the paracetamol study first and three the aspirin study first.

Study II Ionic fluxes Our methodology has been described in detail elsewhere (Ivey and Clifton, 1971a; Ivey et al., 1972a; Ivey and Clifton, 1974). Because of our previous finding (lvey and Schedl, 1970a) of adsorption of indicator to gastric mucosa during the first 15-minute period of exposure to test solution, the stomach was first exposed to $200 \mathrm{ml}$ control acid test solution for 15 minutes. Gastric contents were then aspirated and discarded. Each subject was then studied for four 15-minute periods: the first with control, and the remaining three with paracetamol test solution. In brief, $200 \mathrm{ml}$ test solution was instilled into the stomach at the beginning of each study period. This was mixed rapidly with residual gastric contents and sampled. Exactly 15 minutes later gastric contents were aspirated as fully as possible and the residual volume recovered by rinsing with wash solution. Net ion flux = amount of ion aspirated + amount of ion emptied - amount of ion initially present (Ivey and Clifton, 1974). A positive flux indicates a net addition of ions to the lumen. A negative flux indicates a net loss of an ion from the lumen. All samples were tested for bilirubin by Ictotest tablets and those more than a trace positive were discarded. PD was monitored as in study I continuously through the control and paracetamol test periods.

\section{STATISTICS}

Student's $t$ test was used to analyse paired and unpaired observations. A P value $<0.05$ was regarded as significant.

\section{Results}

Study I Potential difference Mean gastric mucosal PD during the control saline instillation was about - $45 \mathrm{mV}$ (Fig. 1), mucosa negative with respect to serosa. The slight fall in PD after paracetamol instillation was not significant. Similar small falls in PD occurred with repeated instillation of saline solution and were attributed to the mechanical effect of injecting the solution with a syringe into the stomach through the nasogastric tube to which the stomach electrode is attached. Other workers have shown 


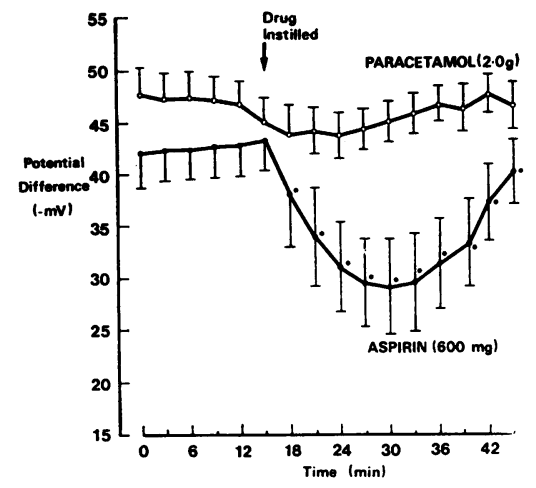

Fig. 1 Effect of paracetamol and aspirin on transmucosal potential difference. Each point is mean of 10 experiments in five subjects. Vertical bars represent mean $\pm S E$ of mean. *Values significantly different from control $(\mathrm{P}<0.05)$.

small insignificant falls in PD after drug instillation in man (Murray et al., 1974).

Aspirin caused a significant fall in PD of $15 \mathrm{mV}$ (Fig. 1). Fall in PD was rapid, and significantly different from control at three minutes $(P<0.05)$, reaching a maximum effect 15 minutes after instillation $(\mathrm{P}<0.001)$. PD did not quite return to baseline $(\mathrm{P}<0.05)$ at the end of the 30 -minute aspirin instillation period, but recovered during the subsequent 30-minute control saline period. Reinstillation of aspirin followed by saline produced an identical fall and recovery of PD. The fall in PD after aspirin was significantly greater than that after paracetamol at all points from 12-27 minutes after drug instillation $(P<0.01$; time $27-42$ minutes, Fig. 1).

Study II Ion fluxes and volumes Net fluxes of $\mathrm{H}^{+}$ and $\mathrm{Na}^{+}$ions and volumes secreted and emptied were not significantly different between control and paracetamol periods (Table). Changes in electrolyte concentrations were also not significantly different between control and paracetamol periods. Mean $\pm \mathrm{SE}$ values for changes in $\mathrm{H}^{+}$were $-17.1 \pm 4.4 \mathrm{mEq} / \mathrm{l}$ in the control period and $-15.7 \pm 1.5 \mathrm{mEq} / \mathrm{l}$ during

Table Net ionic fluxes and volumes secreted and emptied during control and paracetamol studies $($ mean $\pm S E)$

\begin{tabular}{llllll}
\hline Study & \multicolumn{2}{l}{ Net flux $(\mathrm{mEq} / 15 \mathrm{~min})$} & & \multicolumn{2}{l}{ Volumes $(\mathrm{ml} / 15 \mathrm{~min})$} \\
\cline { 2 - 3 } \cline { 5 - 6 } & $H^{+}$ & $\mathrm{Na}^{+}$ & & Secreted & Emptied \\
\hline Control & $-0.56 \pm 0.63$ & $1.47 \pm 0.46$ & $27 \pm 10$ & $30 \pm 7$ \\
Paracetamol & $0.36 \pm 0.27$ & $1.17 \pm 0.10$ & $21 \pm 7$ & $41 \pm 6$ \\
\hline
\end{tabular}

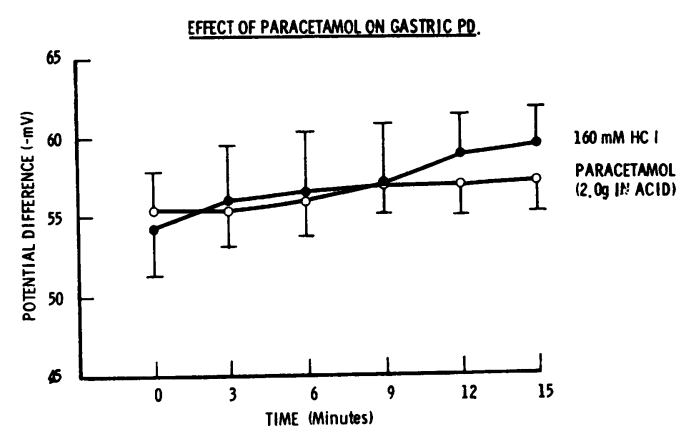

Fig. 2 Effect of paracetamol in acid solution on transmucosal potential difference. Control values were for acid alone. Each point is mean $\pm S E$ of mean of 15 experiments in five subjects for paracetamol and five experiments in five subjects for acid.

the paracetamol periods; corresponding mean $\pm \mathrm{SE}$ values for $\mathrm{Na}^{+}$were $6.8 \pm 1.6 \mathrm{mEq} / \mathrm{l}$ in the control period and $6.2 \pm 0.8 \mathrm{mEq} / 1$ during the paracetamol periods.

POTENTIAL DIFFERENCE DURING ACID INSTILLATION PERIODS

PD remained constant throughout control and paracetamol in acid instillation periods (Fig. 2).

\section{Discussion}

Apart from aspirin, paracetamol is the analgesic most widely used by the general public. Its considerable increase in sales is due largely to its reputation for being free from gastric side-effects. This reputation has been based on indirect assessment of gastric bleeding by measurement of stool blood loss (Goulston and Skyring, 1964) and also on gastroscopic studies which show no macroscopically visible small ulcers and inflammation compared with aspirin (Vickers, 1967).

Both these techniques tend to underestimate the incidence of drug-induced mucosal damage. Studies of blood loss in stools show an overall incidence of increased blood loss in only $50-70 \%$ of subjects given large doses of aspirin, $1 \mathrm{~g}$ three times daily, for three days (Matsumoto and Grossman, 1959; Grossman et al., 1961; Goulston and Skyring, 1964). Vickers' (1967) direct gastroscopic study using a routine $650 \mathrm{mg}$ dose of aspirin found only a $17 \%$ incidence of macroscopically visible lesions. Even when this dose was given with a relatively large dose of acid $(10 \mathrm{mEq})$ by Thorsen et al. in 1968, only a $50 \%$ incidence of abnormalities by gastrocamera examination could be found. 
We have reported, however, a $100 \%$ incidence of microscopic abnormalities after a single dose of aspirin (Ivey et al., 1975a). Approximately 10 minutes after aspirin instillation, $25 \%$ of surface epithelial cells examined show structural damage. These changes correlated well with alterations in potential difference measured at the time biopsies were taken (Ivey et al., 1975a).

In the present study significant changes in PD were produced by $600 \mathrm{mg}$ aspirin. Paracetamol in a dose four times the recommended dose had no such effect. Since aspirin-induced changes in PD are closely correlated with structural and ultrastructural changes in gastric mucosa (Ivey et al., 1975a), the absence of a significant fall in PD after paracetamol is suggestive evidence that this drug produced less gastric damage than aspirin.

The ability of a drug to alter ionic permeability is another measure of damage to gastric mucosa. Previous studies in man have shown that agents which injure gastric mucosa such as bile salts (Ivey et al., 1970b, 1971b), aspirin and salicylic acid (Ivey et al., 1972a; Ivey and Gray, 1972b; Ivey et al., 1975b) alter permeability to $\mathrm{H}^{+}$and $\mathrm{Na}^{+}$movement.

Our studies show that four times the recommended dose of paracetamol has no significant effect on net movement of $\mathrm{Na}^{+}$or $\mathrm{H}^{+}$. Previous studies by us in healthy volunteers have shown that salicylic and acetylsalicylic acids significantly alter net movement of $\mathrm{H}^{+}$and $\mathrm{Na}^{+}$across the gastric mucosa in man (Ivey et al., 1972a; Ivey and Gray, 1972b; Ivey et al., $1975 b)$. For comparison, mean \pm SE control values (Ivey et al., 1972a) for $\mathrm{H}^{+}$and $\mathrm{Na}^{+}$ions were 0.07 \pm 0.15 and $0.84 \pm 0.12 \mathrm{mEq}$ per 15 minutes and after salicylates $-0.99 \pm 0.13$ and $1.54 \pm 0.14$ respectively.

During our acid flux studies with paracetamol, PD was recorded continuously as a second modality of gastric mucosal barrier function. In previous acid flux studies we (Ivey et al., 1975b) and others (Smith et al., 1971) have found a significant fall in PD induced by aspirin. Paracetamol induced no such fall.

We conclude that in contrast with aspirin, paracetamol in 'analgesic' doses does not altet either potential difference or net movement of $\mathrm{H}^{+}$or $\mathrm{Na}^{+}$ ions across man. In limited studies of structural damage induced by paracetamol in man, minimal to no damage was found in contrast with marked changes produced by aspirin (Ivey et al., 1975c). Whether paracetamol is completely free of damaging effects on gastric mucosa awaits further ultrastructural studies.

\section{References}

Andersson, S., and Grossman, M. I. (1965). Profile of pH, pressure, and potential difference at gastroduodenal junc- tion in man. Gastroenterology, 49, 364-371.

Davenport, H. W. (1965). Damage to the gastric mucosa: effects of salicylates and stimulation. Gastroenterology, 49, 189-196.

Geall, M. G., Phillips, S. F., and Summerskill, W.H. J.(1970), Profile of gastric potential difference in man: effects of aspirin, alcohol, bile and endogenous acid. Gastroenterology, 58, 437-443.

Goulston, K., and Skyring, A. (1964). Effect of paracetamol (N-acetyl-p-aminophenol) on gastrointestinal bleeding. Gut, 5, 463-466.

Grossman, M. I., Matsumoto, K. K., and Lichter, R. J. (1961). Fecal blood loss produced by oral and intravenous administration of various salicylates. Gastroenterology, 40, 383-388.

Ivey, K. J., Baskin, W. N., Krause, W., and Jeffrey, G. E. (1975a). Aspirin-induced ultrastructural changes in human gastric mucosa. Correlation with changes in potential difference. Clinical Research, 23, 519A.

Ivey, K. J., and Clifton, J. A. (1971a). Ionic movement across the gastric mucosa of man: reproducibility and effect of intravenous atropine. Journal of Laboratory and Clinical Medicine, 78, 753-764.

Ivey, K. J., and Clifton, J. A. (1974). Back diffusion of hydrogen ions across gastric mucosa of patients with gastric ulcer and rheumatoid arthritis. British Medical Journal, 1, 16-19.

Ivey, K. J., and DenBesten, L. (1971). Gastric volumes aspirated from antrum and fundus in man. American Journal of Digestive Diseases, 16, 123-127.

Ivey, K. J., DenBesten, L., and Clifton, J. A. (1970b). Effect of bile salts on ionic movement across the human gastric mucosa. Gastroenterology, 59, 683-690.

Ivey, K. J., DenBesten, L., and Clifton, J. A. (1971b). Effect of intragastric bile salts on ionic movement across normal human gastric mucosa after intravenous atropine. Gut, 12, 257-261.

Ivey, K. J., and Gray, C. (1972b). Effect of intravenous salicylates on the gastric mucosal barrier in man. American Journal of Digestive Diseases, 17, 1055-1064.

Ivey, K. J., Morrison, S., and Gray, C. (1972a). Effects of salicylates on the gastric mucosal barrier in man. Journal of Applied Physiology, 33, 81-85.

Ivey, K. J., Parsons, C., and Weatherby, R. (1975b). Effect of prednisolone and salicylic acid on ionic fluxes across the human stomach. Australian and New Zealand Journal of Medicine, 5, 408-412.

Ivey, K. J., and Schedl, H. P. (1970a). Gastric non-absorbable indicators for studies in man. Gastroenterology, 59, 234-239.

Ivey, K. J., Settree, P., and Gemmell, R. (1975c). Comparison of acetaminophen and aspirin on gastric mucosal barrier in man. Correlation with ultrastructural changes. Gastroenterology, 68, 918. (Abstract.)

Matsumoto, K. K., and Grossman, M. I. (1959). Quantitative measurement of gastrointestinal blood loss during ingestion of aspirin. Proceedings of the Society for Experimental and Biological Medicine, 102, 517-519.

Murray, H. S., Strottman, M. P., and Cooke, A. R. (1974). Effect of several drugs on gastric potential difference in man. British Medical Journal, 1, 19-21.

Smith, B. M., Skillman, J. J., Edwards, B. G., and Silen, W. (1971). Permeability of the human gastric mucosa. Alteration by acetylsalicylic acid and ethanol. New England Journal of Medicine, 285, 716-721.

Thorsen, W. B., Jr, Western, D., Tanaka, Y., and Morrissey, J. F. (1968). Aspirin injury to the gastric mucosa. Archives of Internal Medicine, 121, 499-506.

Vickers, F. N. (1967). Mucosal effects of aspirin and acetaminophen: report of a controlled gastroscopic study Gastrointestinal Endoscopy, 14, 94-99. 